\title{
QUASI-STATIC AND DYNAMIC SLED TESTING OF PROTOTYPE COMMUTER RAIL PASSENGER SEATS
}

\author{
Kristine Severson \\ A. Benjamin Perlman \\ Volpe National Transportation Systems Center \\ US Department of Transportation \\ Cambridge, MA 02142 USA \\ Richard Stringfellow \\ TIAX LLC \\ Cambridge, MA 02140 USA
}

\section{ABSTRACT}

In support of the Federal Railroad Administration's (FRA) Railroad Equipment Safety Program, tests have been conducted on prototype commuter rail passenger seats which have been designed for improved occupant protection during commuter train accidents. Quasi-static tests were conducted to evaluate the moment versus rotation behavior of the seat back and to improve the fidelity of the finite element seat model. Dynamic sled tests were conducted with instrumented Hybrid III anthropomorphic test devices (ATDs) to evaluate occupant protection under collision conditions and to improve the fidelity of seat/occupant computer models.

The three-passenger prototype seats were designed to meet the following dynamic test requirements:

1. Seats must remain attached to the test fixture.

2. Occupants must be compartmentalized between seat rows.

3. Injury criteria for the head, chest, neck and femur must be within tolerance thresholds specified by the automotive industry.

4. All seat components, including seat cushions, must remain attached.

Test conditions were specified for two dynamic sled tests as follows: three forward-facing $50^{\text {th }}$ percentile male Hybrid III ATDs subjected to an $8 \mathrm{G}, 250$ millisecond triangular crash pulse; and three rear-facing $50^{\text {th }}$ percentile male Hybrid III ATDs subjected to a $12 \mathrm{G}, 250$ millisecond triangular crash pulse. The $8 \mathrm{G}$ crash pulse is specified in the existing American Public Transportation Association (APTA) Standard for Rowto-Row Seating in Commuter Rail Cars [1] and in the Federal Code of Regulations 49 CFR 238.233 [2], and represents nominal collision conditions. The $12 \mathrm{G}$ crash pulse represents the collision environment measured in the cab car during a
\end{abstract}

previous full-scale train-to-train impact test of passenger rail cars incorporating crash energy management $[3,4]$.

The final test results indicate that all test requirements were met: the seats remained attached to the test sled; the ATDs were compartmentalized; all the injury criteria were within accepted tolerance thresholds; and all the seat cushions remained attached.

\section{INTRODUCTION}

The commuter seats described in this paper were developed specifically for use in rail cars utilizing crash energy management (CEM) features, though the seats would also be expected to perform well in conventional cars. Analysis and test results of some CEM equipment have indicated the potential for severe secondary impacts when compared to conventional equipment, especially when the cars are relatively light. Previous experiments using commuter seats in conventional equipment tests $[5,6]$ indicated that the baseline, M-style commuter seat needed only minor modifications to meet the existing crashworthiness requirements [1,2]. The results from the two-car CEM impact test [7], however, indicated a severe secondary impact environment. As CEM features absorb collision energy without excessive amounts of crushed occupant volume, the decelerations are greater in the car interior when compared to conventional equipment. Consequently, occupants in CEM equipment may have a higher secondary impact velocity. Here, larger amounts of kinetic energy need to be absorbed by the impacted seats. The first car in a CEM consist generally has a more severe crash pulse than the trailing cars. Much of the negative effect of this more severe impact environment can be mitigated by placing rearfacing seats in the lead car. An improved seat design was necessary to meet the seat performance requirements under the collision conditions in the leading cars of this CEM design. 
Performance-based requirements for the prototype seat were defined under forward-facing $8 \mathrm{G}$ and rear-facing $12 \mathrm{G}$ test conditions, which were described in a previous ASME paper [8]. These requirements exceed those specified in the Code of Federal Regulations Passenger Equipment Safety Standards, CFR49 part 238 [2] and the APTA seat standard. The APTA standard specifies that under forward-facing $8 \mathrm{G}$ test conditions, the seats must remain attached to the test fixture at all attachment points and permanent seat deformations must not impede an occupant from standing and exiting the seat. The ATDs must be compartmentalized. The head, chest, and femur injury criteria must be below maximum thresholds (which are defined later in this paper). All seat components, including seat cushions, must remain fastened to the seat. Under rear-facing $8 \mathrm{G}$ test conditions, the same requirements must be met, but there are no injury requirements.

In addition to the requirements in the current APTA standard, the prototype seat is subject to additional requirements. Under rear-facing $12 \mathrm{G}$ test conditions, the seat must meet all of the requirements specified for the forwardfacing $8 \mathrm{G}$ test, including injury criteria. The prototype seat must also meet neck injury criteria in the forward- and rearfacing tests, which currently aren't required under the APTA Standard.

The prototype commuter seat was initially tested in rearfacing and forward-facing occupant experiments during the train-to-train test of CEM equipment in March 2006 [4]. It was anticipated that large reaction forces would occur at the seat attachment points. However, the reaction loads were even larger than expected and the seat attachment strength was less than expected. In both experiments, the seat separated from the car at one or more attachment points. Subsequently, the seat base, pedestal, and attachments were strengthened to improve performance.

\section{SEAT DESIGN}

The seat design developed was based on an existing twopassenger seat design. A three-passenger seat design was chosen for this project because it provides a direct comparison to the previous full-scale occupant experiments and sled test results in which three-passenger M-Style seats were used. There continue to be many three-passenger seats in service, even though the Americans with Disabilities Act (ADA) has prompted many commuter rail operators to discontinue use of the three-passenger seat in favor of a two-passenger seat. Also, the three-passenger seat presents a worst-case scenario when compared to a two-passenger seat. It must withstand 50percent higher loads during a collision due to the additional occupant. This particular seat design can easily be modified to a two-passenger seat design that would also meet the same crashworthiness requirements.

The seat design utilizes modular seating, which consists of an individual seat pan and seat back for each passenger. This system provides each passenger a similar level of protection, regardless of seat occupancy. Each seat frame is made of round steel tubes (see seat schematic in Figure 1) and is designed to absorb energy during a collision. A knee bolster is welded to the vertical seat back tubes to transfer the inertial load from either a forward-facing or rear-facing occupant into the seat frame structure. The seat tubes are designed to deform plastically to absorb kinetic energy imparted by an occupant, but not to the extent that compartmentalization is lost.

The seat back and seat bottom cushions consist of foam bonded to aluminum sheet metal, covered with a fabric upholstery. Plastic shrouds cover the back and the bottom of each seat. The individual seat assemblies are fastened to a steel box-shaped channel via rivet nuts, which is supported by a steel box-shaped pedestal and a wall mount. The channel and pedestal are bolted to the wall and floor supports, respectively.

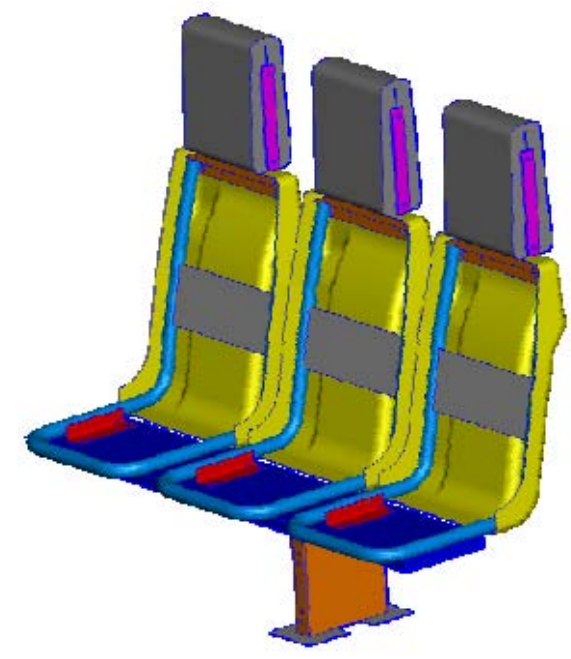

Figure 1. Schematic of Prototype Commuter Seat Frame

Each seat includes a separate headrest. Foam padding is bonded to a sheet of aluminum that has been preformed to fit over a steel frame (see schematic in Figure 2). The assembly is then bolted to the top of the seat back. The head rest is padded on both sides to provide protection in both forward- and rearfacing impacts. 


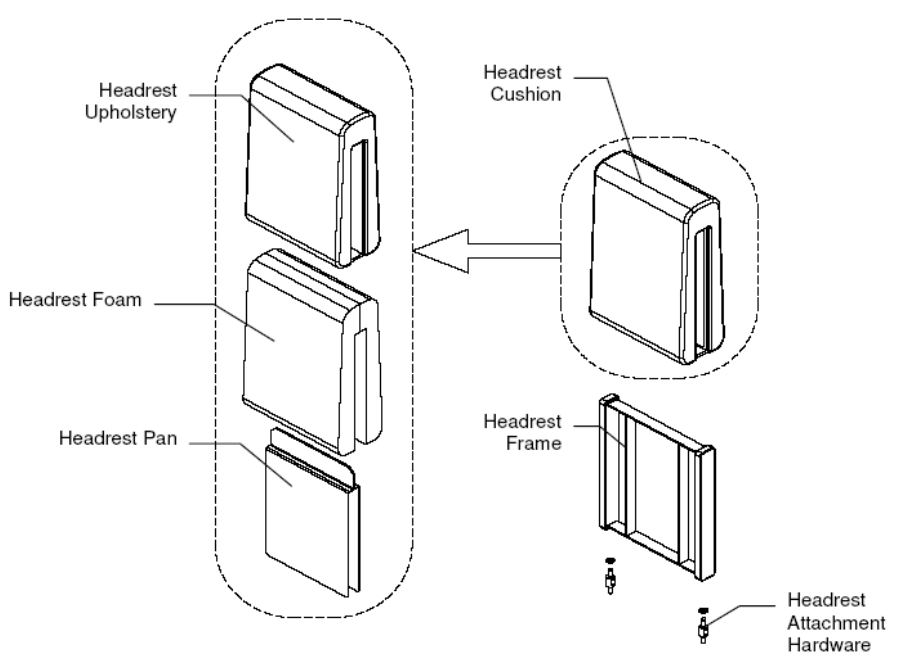

Figure 2. Schematic of Head Rest Assembly

The original seat design was modified in order to meet the design requirements of this project. The support channel was lengthened to accommodate an additional seat position. Strength requirements for the tube material were increased to improve the energy absorption capability. The head rest was extended upward by three inches to help prevent the loss of compartmentalization, and to minimize neck injury in the rearfacing configuration. A stiffer foam was used in the head rest to minimize head injury. A plate was added to the bottom of the channel to increase its torsional stiffness. The welded connections between the pedestal and the floor and channel were strengthened and reinforced with bolted angle brackets (see schematic in Figure 3). A rubber spacer was added to the seat bottom assembly to prevent disengagement of the cushion retention clips.

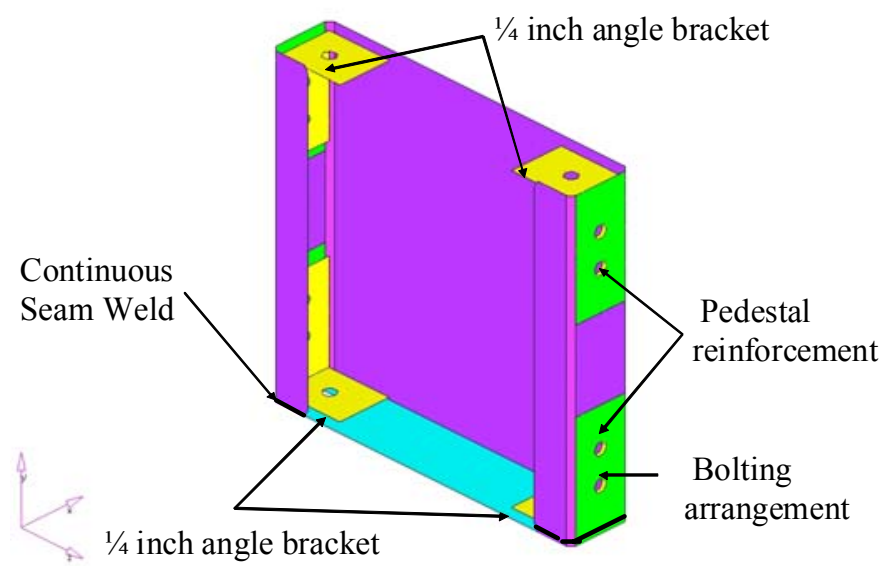

Figure 3. Schematic of Seat Pedestal

\section{TEST DESCRIPTIONS AND RESULTS}

\section{Quasi-Static Seat Testing}

On October 16-18, 2006, three quasi-static tests of prototype three-passenger commuter rail seats were conducted. The seats used in these tests were modified subsequent to the train-to-train test of CEM equipment in March 2006 in which the seats were not adequately attached to the car body. The seat channel, pedestal, and pedestal attachments were strengthened to improve performance.

The tests were conducted to measure force versus displacement behavior of the seat back (from which the moment versus rotation of the seat back was calculated), and to verify that the seats remained attached to the test fixture under these loading conditions. The test results were subsequently used to fine-tune finite element computer models of the seat.

For each destructive test, a new seat was fastened to the test fixture. The seat was instrumented to measure triaxial reaction load time-histories at the floor and wall attachment points, as well as uniaxial displacement time-histories at several hard points on the seat. The load was applied to each seat back via three hydraulic cylinders. Three uniaxial load cells and string potentiometers were in place to measure the force and displacement time-histories of the loading ram at the individual seat backs during each test.

Test 1 applied the load to the seat back cushions in the rear-facing direction via three rigid torso blocks that were positioned in the seats. The test represented the loading due to the body of a rear-facing occupant. Tests 2 and 3 applied the load to the seat back in the forward-facing direction, at the height of the knee bolster and head rest, respectively. These tests represented the loading due to the knees and head of a forward-facing occupant.

The reaction force versus time was measured, and the moment versus rotation of each seat back was calculated. The failure mode in each test was bending of the steel seat frame tubes, and no failures of the seat attachments occurred.

For each of the quasi-static tests, the moment versus rotation behavior of the seat back was estimated as follows. The horizontal load applied to the seat back was multiplied by the vertical distance, $X$, between the seat bottom and the load application to calculate the moment acting at the hinge point. The horizontal displacement of the seat back measured by the string potentiometer was scaled by a factor of $\mathrm{X} / \mathrm{Y}$ to approximate the horizontal displacement, $\mathrm{Z}$, of the seat back at the height of load application. This measurement is less than the horizontal displacement of the loading ram which also includes elastic compression of the cushions, plastic shroud, or knee brace. The angle of rotation of the seat back, $\theta$, was approximated by $\arctan (\mathrm{Z} / \mathrm{X})$. For large angles of rotation there will be small second order errors using this procedure. See sketch in Figure 4 for details. 


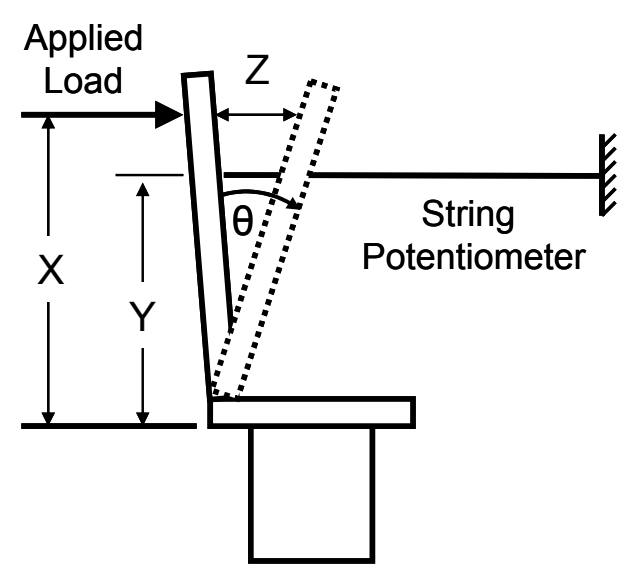

Figure 4. Sketch of Test Measurements

Figure 5 shows pre- and post-test photos of the rear-facing body load test. In this test, the load was applied to the seat back via rigid body blocks at a height of 14.5 inches above the seat bottom, which approximates the location of the center of mass of an occupant.
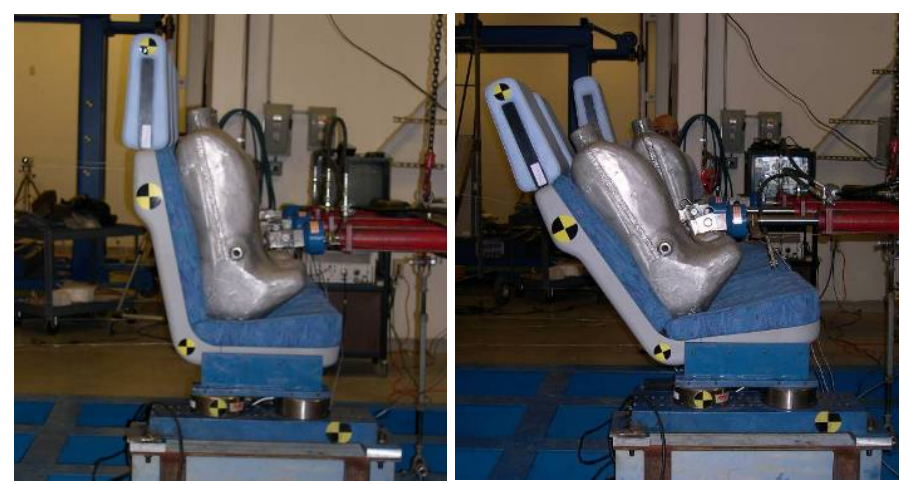

Figure 5. Pre- and Post-Test Photos of Rear-Facing Body Load Test

A plot of the moment versus rotation for each seat, which has been approximated from the measured force versus displacement as described above, is shown Figure 6. Each seat back in this test exhibited similar moment-rotation behavior. The seat backs rotated nearly 20 degrees with moments reaching 30,000 in-lbf per seat. The largest reaction load occurred at the forward load cell under the floor pedestal, which reached a peak of $11,500 \mathrm{lbf}$ in tension.

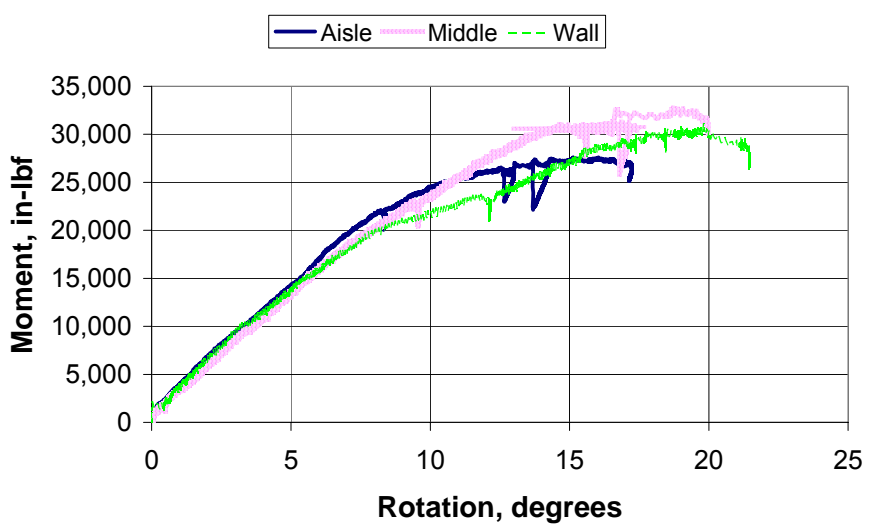

Figure 6. Moment Versus Rotation Behavior from RearFacing Body Load Test

Figure 7 shows pre- and post-test photos of the forwardfacing knee load test. The load was applied to the plastic seat back at a height of 9.5 inches above the seat bottom, in line with the knee bolster.

A plot of the moment versus rotation for each seat back is shown in Figure 8. The middle and aisle seats exhibited similar moment-rotation behaviour. The seat backs rotated nearly 15 degrees at a moment of over 20,000 in-lbf before a plastic hinge developed in the steel tube at the angle between the seat bottom and seat back.

The window seat formed a plastic hinge at a slightly lower moment of 17,500 in-lbf, which was likely due to the constraint of the wall attachment. Torsion of the seat channel to which the seat tubes were mounted enabled the middle and aisle seats to carry a higher load before forming a plastic hinge. The largest reaction load in this test occurred at the rear load cell under the floor pedestal, which reached a peak of 9,800 lbf in tension.
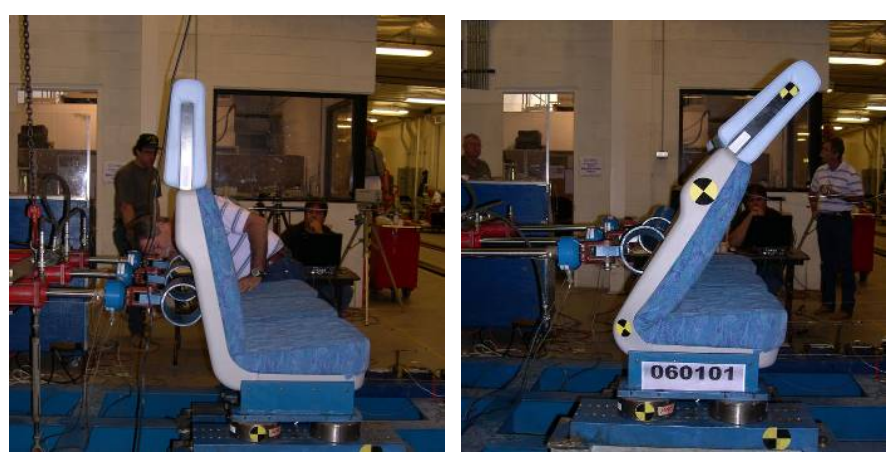

Figure 7. Pre- and Post-Test Photos of Forward-Facing Knee Load Test 


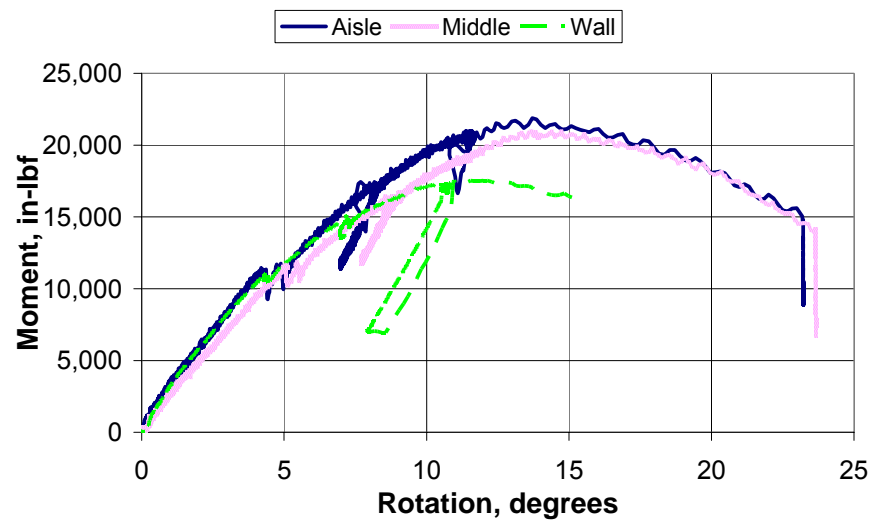

Figure 8. Moment Versus Rotation Behavior from Forward-Facing Knee Load Test

Figure 9 shows pre- and post-test photos of the forwardfacing head load test. In this test, the load was applied to the middle of the head rest at a height of 32.5 inches above the seat bottom, which approximates the location of an occupant's head impact.

A plot of the moment versus rotation for each seat back is shown in Figure 10. Each seat back exhibited similar momentrotation behavior. The seat backs rotated forward 10-12 degrees at moments of 18,000-20,000 in-lbf before a plastic hinge developed. The largest reaction load in this test occurred at the rear load cell under the floor pedestal, which reached a peak load of 5,200 lbf in tension.
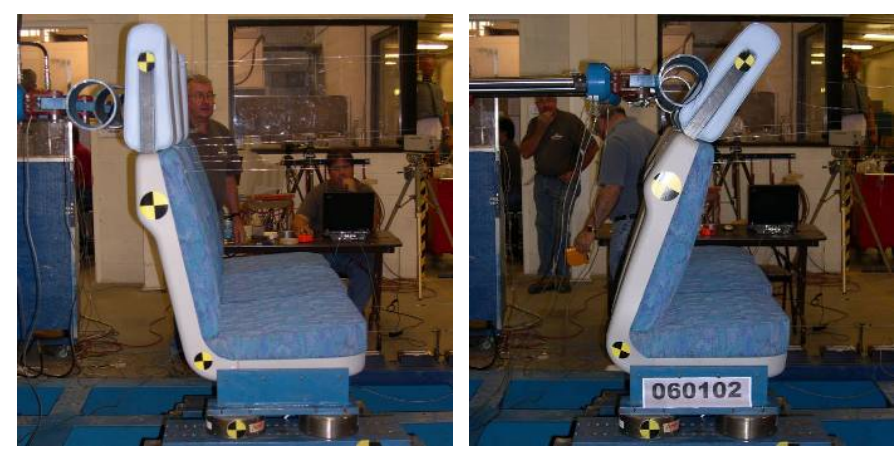

Figure 9. Pre- and Post-Test Photos of Forward-Facing Head Rest Test

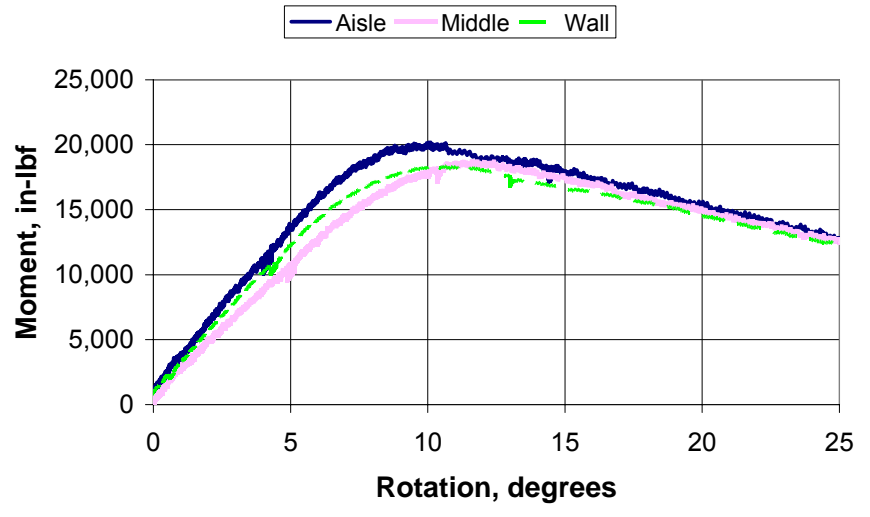

Figure 10. Moment Versus Rotation Behavior from Forward-Facing Head Load Test

\section{Dynamic Seat Testing}

On October 25-26, 2006, two dynamic sled tests with instrumented anthropomorphic test devices (ATDs) were conducted. The seats used in these tests were identical to the seats used in the quasi-static tests, which included design improvements that were incorporated following the CEM trainto-train test.

The first test used forward-facing seats and ATDs with an $8 \mathrm{G}$ crash pulse. The second test used rear-facing seats and ATDs with a $12 \mathrm{G}$ crash pulse. Each test included three $50^{\text {th }}$ percentile male Hybrid III ATDs. The ATDs in the aisle and window position were instrumented to measure triaxial head and chest acceleration, axial femur loads, and uniaxial moment and biaxial forces on the upper neck.

For each test, two rows of seats were mounted to the test sled with a 32 inch seat pitch. The seats were instrumented to measure triaxial reaction load time-histories at the floor and wall attachment points. Redundant accelerometers were placed on the test sled to measure longitudinal acceleration.

The longitudinal sled system is operated by connecting the front of the sled to a drop weight through a pulley and cable system. The rear end of the sled is connected to a haul-back winch via a cable system. By pulling the sled back a calculated distance and locking it to a release mechanism, the drop weight is raised, storing the potential energy required to accelerate the sled down the track towards a cardboard honeycomb stack placed directly in front of a rigid impact barrier. A "dozer" plate is mounted on the front of the sled to impact the stack of honeycomb cardboard, which is stacked in a predetermined configuration to decelerate the sled and produce the desired deceleration time-history, or crash pulse.

Figure 11 shows the idealized triangular crash pulse and the actual crash pulse that was measured during the forwardfacing $8 \mathrm{G}$ sled test. The area under the curve, which is the total change in velocity, is $22 \mathrm{mph}$ for the idealized pulse and 21.7 for the actual pulse. The test crash pulse was acceptable in that it met the requirements specified in SAE AS8049, Performance 
Standard for Seats in Civil Rotorcraft, Transport Aircraft, and General Aviation Aircraft [9].

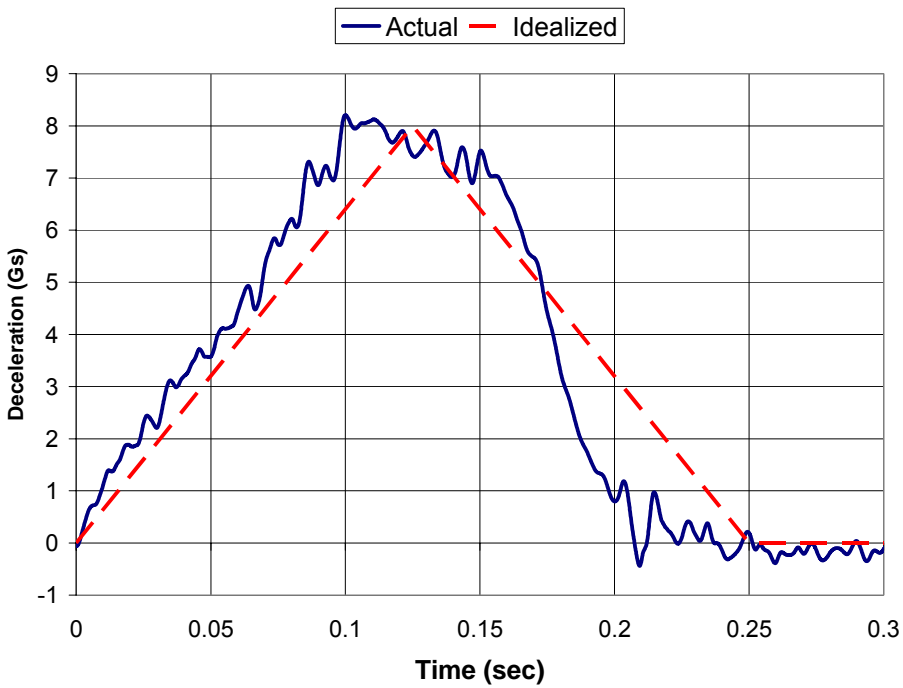

Figure 11. Plot of Idealized and Actual Crash Pulse for Forward-Facing 8G Sled Test

Figure 12 and Figure 13 show pre- and post-test photos from the forward-facing sled test. The seats remained attached to the test sled with no visible deformation at the seat attachments. The ATDs were compartmentalized. The aisle dummy fell off the sled post-impact, but was effectively compartmentalized per the definition in the APTA Standard for Row-to-Row Seating in Commuter Rail Cars [1]. All injury criteria were below the maximum thresholds. All cushions remained attached.

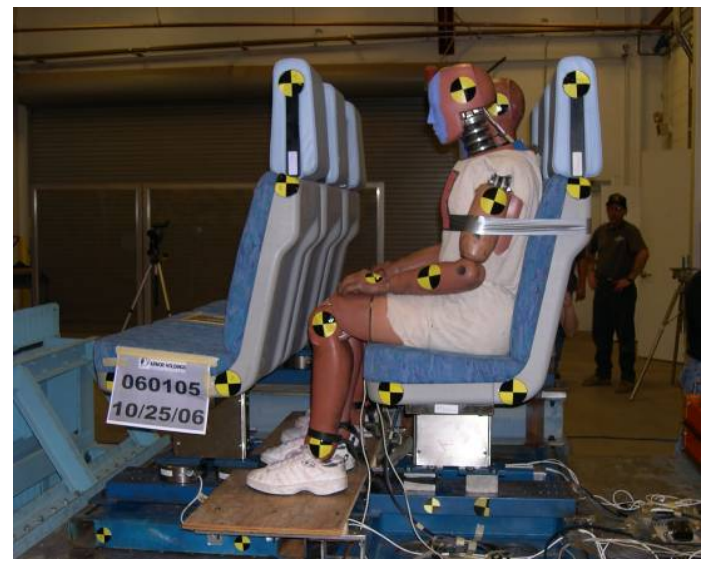

Figure 12. Pre-Test Photo of Forward-Facing 8G Sled Test

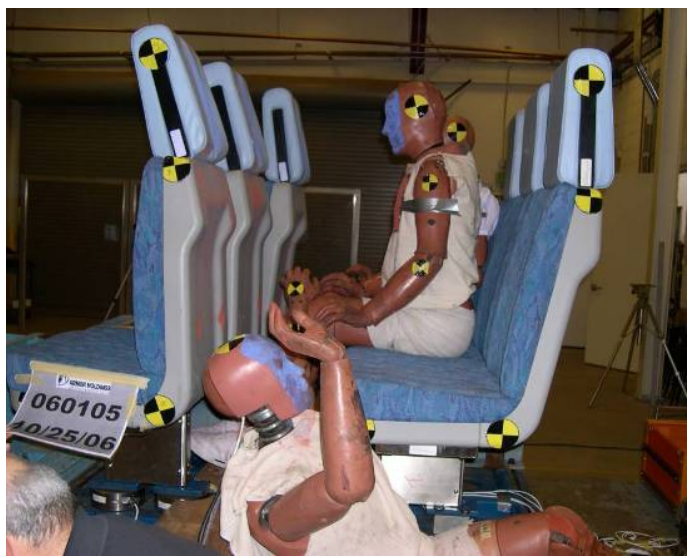

Figure 13. Post-Test Photo of Forward-Facing 8G Sled Test

Once the test sled impacted the cardboard honeycomb, it began to decelerate. The ATDs continued to translate forward with respect to the seats at the velocity just prior to impact. The ATDs' knees impacted the seat backs first, loading and slightly deforming the knee bolsters, and transferring the load into the seat back frames, initiating plastic deformation of the seat back. The ATDs' heads then impacted the head rests and the chests impacted the top of the seat backs. The seat backs deformed to a maximum plastic rotation of between 6 degrees (window seat) and 15 degrees (aisle seat), as determined from pre- and post-test angle measurements of the seat back with respect to vertical.

The head rests provided a compliant impact surface which minimized head deceleration. The foam padding deformed and transferred load to the aluminum sheet metal, which deformed plastically to absorb energy (see headrest photo in Figure 14).

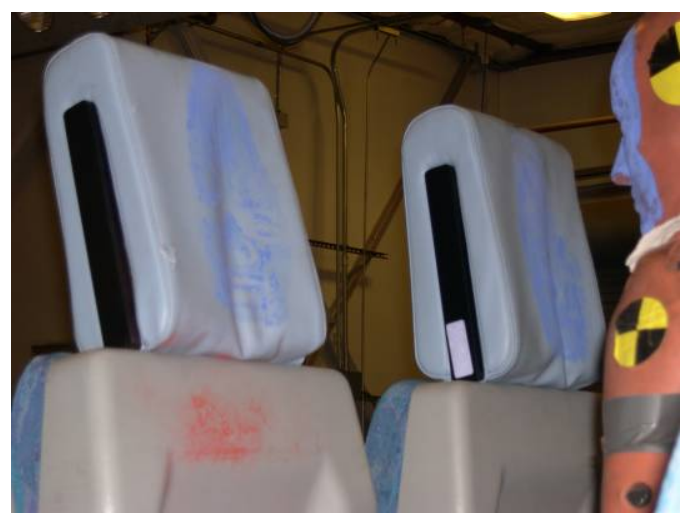

Figure 14. Post-Test Photo of Head Rests

All test data was recorded. All channels appeared to function properly, with the exception of the left femur load and the $\mathrm{M}_{\mathrm{y}}$ neck moment in the aisle ATD**. Consequently, the $\mathrm{N}_{\mathrm{ij}}$ data is not complete. Based on the neck $F_{x}$ and $F_{z}$ load time histories alone, and the injury results of the ATD in the window seat, which were slightly more severe, it is nearly certain that the maximum $\mathrm{N}_{\mathrm{ij}}$ for the aisle ATD would have been lower than 
the 0.50 maximum $\mathrm{N}_{\mathrm{ij}}$ for the window ATD, and well below the maximum allowed value of 1.0 .

The injury results for the forward-facing $8 \mathrm{G}$ test are listed in Table 1. All of the injury results are below the maximum allowable thresholds, which are taken from the Federal Motor Vehicle Safety Standards [10]. The injury results were modestly higher for the ATD in the window seat position. The effective stiffness of the window seat was slightly higher than the aisle seat due to a small amount of torsion of the seat channel.

Table 1. Injury Results for Forward-Facing 8G Sled Test

\begin{tabular}{|l|c|c|c|}
\hline Criteria & $\begin{array}{c}\text { Injury } \\
\text { Threshold } \\
{[10]}\end{array}$ & $\begin{array}{c}50^{\text {th }} \text { Percentile } \\
\text { Male, } \\
\text { Window Seat }\end{array}$ & $\begin{array}{c}50^{\text {th }} \text { Percentile } \\
\text { Male, } \\
\text { Aisle Seat }\end{array}$ \\
\hline HIC15 & 700 & 560 & 260 \\
\hline Nij & 1.0 & $\begin{array}{l}0.50(\mathrm{Ntf}) \\
0.31(\mathrm{Nte}) \\
0.46(\mathrm{Ncf}) \\
0.20(\mathrm{Nce})\end{array}$ & $* *$ \\
\hline Peak Neck & $+937 /-899$ & $+480 /-280$ & $+140 /-180$ \\
Fz, lbf & 60 & 28 & 19 \\
\hline Chest g & 2,250 & 970 & $* *$ \\
\hline Femur & 920 & 700 \\
\hline Load, lbf & & & \\
\hline
\end{tabular}

The peak reaction loads for each load cell are given in Figure 15. The critical load is assumed to be the vertical tensile load in the rear load cell under the pedestal, since this is where the failure initiated in the forward-facing occupant experiment in the CEM train-to-train test. The peak load measured at this position in the train-to-train test was $6,830 \mathrm{lbf}$, at which point the attachment failed. The peak load measured at the same position in the sled test was 9,850 lbf. The sled test demonstrated that the modifications to the pedestal attachment resulted in a significant improvement in the attachment strength.

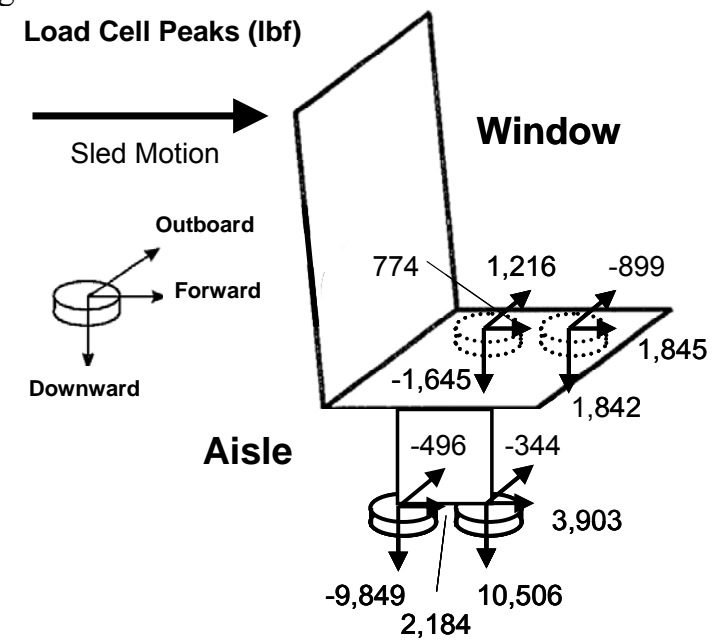

Figure 15. Schematic of Peak Reaction Loads in ForwardFacing 8G Sled Test
The first rear-facing $12 \mathrm{G}$ sled test was conducted in October, 2006. In that test, the maximum vertical tensile loads were nearly twice that of the failure loads measured during the full-scale test, indicating that the seat modifications resulted in a significant strength improvement. In this test, the pedestal did not deform, but the rear bolts under the pedestal fractured.

Subsequently, the seat design was analyzed and further modifications were prescribed. The modifications included larger bolts at the floor and wall connection points to prevent seat attachment failure. Two additional riv-nuts per seat position were added to prevent failure of the seat-to-channel attachment. An additional cushion retention clip was added to each seat frame to ensure cushion securement during the $12 \mathrm{G}$ test.

The newly modified seats were successfully tested under the rear-facing $12 \mathrm{G}$ conditions on August 28, 2007. All test conditions were identical to the previous rear-facing test. Figure 16 shows the idealized triangular crash pulse and the actual crash pulse that was measured during the rear-facing $12 \mathrm{G}$ sled test. The area under the curve, which is the total change in velocity, is $32.9 \mathrm{mph}$ for the idealized pulse and 32.7 mph for the actual pulse. The test crash pulse was acceptable in that it met the requirements specified in SAE AS8049 [9].

Figure 17 and Figure 18 show pre- and post-test photos from the rear-facing sled test. The seats remained attached to the test sled with no visible deformation at the seat attachments. The ATDs were clearly compartmentalized. All injury criteria were below the maximum thresholds. All cushions remained attached.

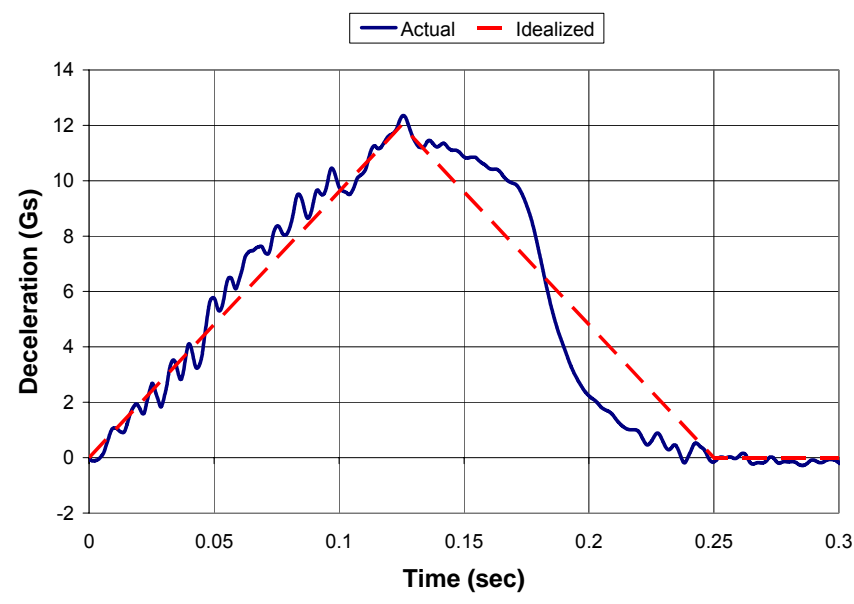

Figure 16. Idealized and Actual Crash Pulses for RearFacing 12G Sled Test 


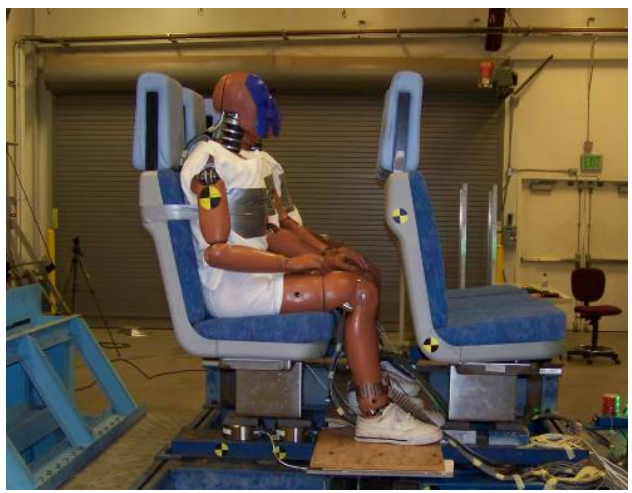

Figure 17. Pre-Test Photo of Rear-Facing 12G Sled Test

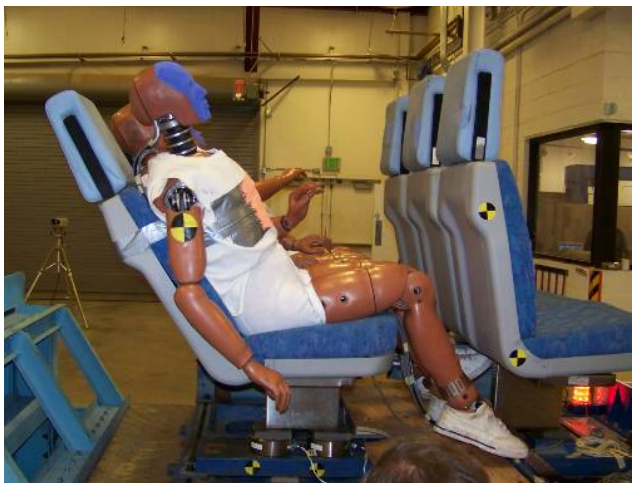

Figure 18. Post-Test Photo of Rear-Facing 12G Sled Test

Upon impact with the cardboard honeycomb, the sled began to decelerate. The ATDs translated backwards into the seat back cushions, with minimal vertical displacement. The heads were well-supported by the head rests. The seat backs then began to deform, reaching a maximum plastic rotation of between 22 and 28 degrees, as determined from pre- and posttest angle measurements of the seat back. It is difficult to determine an upper bound for maximum allowable seat back rotation that will ensure compartmentalization of the ATDs, because other factors contribute to compartmentalization, such as contact friction. Rather than prescribe a maximum allowable rotation of the seat back, the existing APTA seat standard requires that ATDs are compartmentalized during sled testing.

The ATDs rebounded away from the seat backs with minimal velocity relative to the test sled and seats. They came to a stop with their heads resting against the adjacent seat back. They slid forward on the bottom cushion a few inches, but not enough for their knees to make contact with the adjacent seat.

The injury results for the rear-facing $12 \mathrm{G}$ test are listed in Table 2. All of the injury results are less than 25-percent of the maximum allowable thresholds. The results from this sled test indicate that the rear-facing seating configuration provides a high degree of occupant protection under extremely severe collision conditions. All of the injury criteria in this test were below the injury criteria measured in the forward-facing $8 \mathrm{G}$ test, even though the collision energy was over 100-percent higher.

Table 2. Preliminary Injury Results for Rear-Facing 12G Sled Test

\begin{tabular}{|l|c|c|c|}
\hline Criteria & $\begin{array}{c}\text { Injury } \\
\text { Threshold } \\
{[10]}\end{array}$ & $\begin{array}{c}50^{\text {th }} \text { Percentile } \\
\text { Male, } \\
\text { Window Seat }\end{array}$ & $\begin{array}{c}50^{\text {th }} \text { Percentile } \\
\text { Male, } \\
\text { Aisle Seat }\end{array}$ \\
\hline HIC15 & 700 & 17 & 70 \\
\hline & & $0.10(\mathrm{Ntf})$ & $0.15(\mathrm{Ntf})$ \\
Nij & 1.0 & $\begin{array}{l}0.14(\mathrm{Nte}) \\
0.03(\mathrm{Ncf})\end{array}$ & $\begin{array}{c}0.22(\mathrm{Nte}) \\
0.03(\mathrm{Ncf})\end{array}$ \\
& & $+10(\mathrm{Nce})$ & $0.17(\mathrm{Nce})$ \\
\hline Peak Neck & $+937 /-899$ & $+130 /-2$ & $+230 /-10$ \\
Fz, lbf & 60 & 11 & 15 \\
\hline Chest g & 2,250 & 50 & $\mathrm{~N} / \mathrm{A}^{*}$ \\
\hline Femur & & 40 & \\
Load, lbf & & & \\
\hline
\end{tabular}

*The ATD in the aisle position was not equipped with femur load cells.

The peak reaction loads for each load cell are given in Figure 19. The rear-facing $12 \mathrm{G}$ collision environment presents a much more severe collision environment than any of the previous occupant experiments conducted under FRA's Railroad Equipment Safety Program. In the first rear-facing $12 \mathrm{G}$ sled test and the rear-facing occupant experiment on the CEM train-to-train test, the critical load path was through the rear load cell of the pedestal-to-floor attachment, as this was where both seat detachments initiated. In the train-to-train test, the peak load at this position was $6,420 \mathrm{lbf}$ when the attachment failed. In the first rear-facing $12 \mathrm{G}$ sled test the peak load at this position was $13,600 \mathrm{lbf}$ when the attachment failed. In the successful rear-facing $12 \mathrm{G}$ sled test, the peak load measured in the at this position was 14,070 lbf. This load is nearly 50-percent higher than the largest vertical tensile load measured in the forward-facing $8 \mathrm{G}$ sled test. Attention has been drawn to the large reaction loads associated with these extreme collision conditions such that car builders and seat manufacturers designing for similar conditions can be alerted to the high strength requirements. Note that the loads can be expected to be about one-third smaller for two-seat systems. 


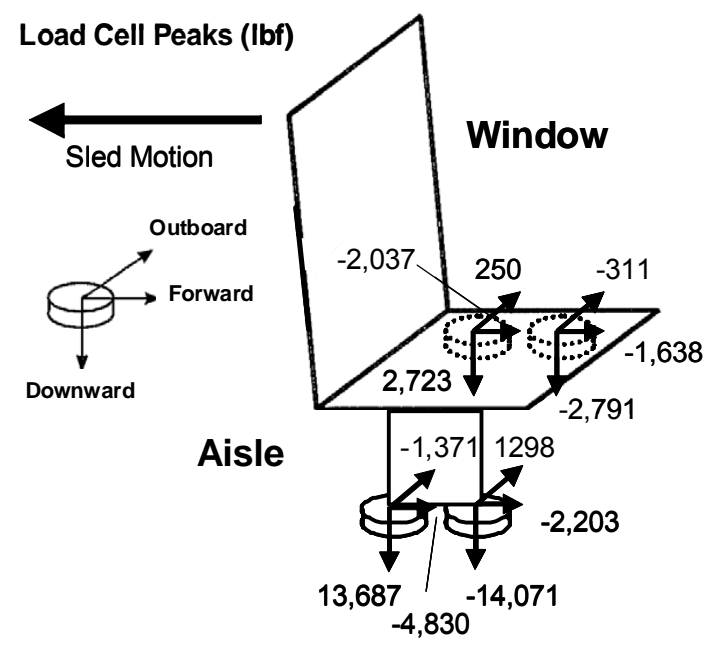

Figure 19. Schematic of Peak Reaction Loads in RearFacing 12G Sled Test

\section{CONCLUSIONS}

A series of quasi-static and dynamic tests were conducted on a prototype commuter seat design. The final seat design met all the design requirements, which exceed the requirements specified in the APTA Standard for Row-to-Row Seating in Commuter Rail Cars [1].

The quasi-static loading tests demonstrated the energyabsorbing capability of the seat back frame. In each test, the applied load caused plastic bending of the tubular steel seat frame at the pre-formed angle between the seat back and bottom, as expected. The seat attachments were able to sustain the applied loads without failure.

The dynamic sled tests demonstrated that this prototype seat design is capable of meeting existing seating requirements, as well as the more onerous design requirements defined for this seat, which include neck injury criteria, and a $12 \mathrm{G}$ crash pulse for the rear-facing seating configuration. The same seat design functions well in both the forward- and rear-facing configurations, minimizing the injury criteria measurements while maintaining occupant compartmentalization.

The rear-facing $12 \mathrm{G}$ sled test also demonstrated that a rearfacing seating configuration can be a successful strategy to mitigate the high deceleration collision environment often associated with the leading cars in CEM equipment. The rearfacing test resulted in even lower injury measurements when compared to the results of the forward-facing $8 \mathrm{G}$ test.

\section{ACKNOWLEDGEMENTS}

This work was performed as part of the Equipment Safety Research Program sponsored by the Federal Railroad Administration's Office of Research and Development. The authors would like to thank Eloy Martinez, Program Manager, and Claire Orth, Division Chief, Equipment and Operating Practices Research Division, Office of Research and
Development, Federal Railroad Administration, for all their support. Additional thanks go to David Tyrell, Program Manager at the Volpe Center, for technical direction; Robert Rancatore, former Program Manager at TIAX LLC, for his efforts in implementing the seat testing; Chris Bradney and his team at Armor Holdings Aerospace and Defense Group (now BAE Systems, Inc.), for executing the seat tests; and Caroline VanIngen-Dunn, of CVID Consulting, for assisting with on-site implementation and reporting of the tests.

\section{REFERENCES}

[1] APTA SS-C\&S-016-99, Rev. 1, Standard for Row-to-Row Seating in Commuter Rail Cars, The American Public Transportation Association, Washington, DC.

[2] Code of Federal Regulations, Title 49, Part 238, Passenger Equipment Safety Standards, Section 233, October, 2003.

[3] Tyrell, D., Jacobsen, K., Martinez, E., Perlman, A.B., "Train-to-Train Impact Test of Crash-Energy Management Passenger Rail Equipment: Structural Results,” American Society of Mechanical Engineers, Paper No. IMECE200613597, November 2006.

[4] Severson, K. J., Parent, D. P., "Train-to-Train Impact Test of Crash-Energy Management Passenger Rail Equipment: Occupant Experiments," American Society of Mechanical Engineers, Paper No. IMECE2006-14420, November 2006.

[5] Tyrell, D., K. Severson, A.B. Perlman, "Passenger Rail Two-Car Impact Test Volume I: Overview and Selected Results," U.S. Department of Transportation, DOT/FRA/ORD01/22.I, January 2002.

[6] VanIngen-Dunn, C., "Passenger Rail Train-to-Train Impact Test Volume II: Summary of Occupant Protection Program," US Department of Transportation, DOT/FRA/ORD-03/17.II, July 2003.

[7] Severson, K., Parent, D., Tyrell, D., "Crash Energy Management Impact Tests: Occupant Tests," American Society of Mechanical Engineers, Paper No. IMECE2004-61249, November 2004.

[8] Severson, K., Tyrell, D., Rancatore, R., "Crashworthiness Requirements for Commuter Rail Seats," American Society of Mechanical Engineers, Paper No. IMECE2005-82643, November 2005.

[9] SAE AS8049, Performance Standard for Seats in Civil Rotorcraft, Transport Aircraft, and General Aviation Aircraft, revised September, 1997.

[10] Code of Federal Regulations, Title 49, Part 571, Section 208, Occupant Crash Protection, October 1, 2002. 